\title{
Literary Texts Selection for Malaysian Lower Secondary Schools in Perak
}

\author{
Revathi Gopal*, Mazlin Mohamed Mokhtar \\ Faculty of Languages and Communication, Sultan Idris Education University, Malaysia
}

Received April 19, 2020 ; Revised May 28, 2020; Accepted June 26, 2020

Copyright $\mathrm{C} 2020$ by authors, all rights reserved. Authors agree that this article remains permanently open access under the terms of the Creative Commons Attribution License 4.0 International License

\begin{abstract}
This paper aims to analyze the selection of literary texts in Malaysian lower secondary schools. Literary text selection involves two factors, the text and the reader. As the study required in-depth knowledge on both the factors, the research design includes quantitative and qualitative research methods. Research design includes quantitative and qualitative research methods. In the first phase of the study, a cross-sectional survey was conducted. A set of questionnaires containing 150 questions was distributed to 450 respondents from Form One to Form Three in five districts in Perak to address students' views on cultural familiarity of the texts, interest and motivation in reading literary texts, and physical features of the literary texts. In the second phase, six Form Two students participated in a retelling session to identify students' strengths and weaknesses in text comprehension. The findings from quantitative data showed positive results especially on cultural aspects. Students from Form One to Form Three understand the cultural aspects portrayed in the short stories. On the physical aspects of the literary texts, Form Two and Form Three students find the cover of their text book to be unattractive. In terms of students' preference of literary texts, Form One to Form Three students preferred reading foreign texts compared to Asian texts. As for the qualitative data, the session on retelling revealed the participants were able to relate main ideas and supporting details sequence the story line in order and understand text organization. The implication of the research indicates the literary texts selected, caters to Malaysian lower secondary students in Perak.
\end{abstract}

Keywords Text Selection, Literary Texts, Cultural Familiarity

\section{Introduction}

The literature component is added to the English
Language syllabus to enhance students' reading skills. They could understand diverse use of words, phrases, phrasal verbs, multiple meanings, and idioms. They learn to use familiar words in new contexts with new meanings. Students get absorbed in the story, the language for example the sentences, phrasal patterns and words are understood and mastered without much effort in the process [1]. They consolidate and build their foundational learning in English related to texts and language. Besides, they can develop an understanding of other societies, cultures, values and traditions that will contribute to their emotional and spiritual growth.

The literary texts selected for lower secondary comprise of short stories, novels, drama and poems. In English language classrooms, students are guided to read the literary texts, understand them and later they are to give their opinions on the genres read. However, students are often reluctant to voice out their opinion, thinking that they might go wrong and will be looked down by their classmates. This situation arises due to their confidence level in understanding the literary text. Text comprehension is dependent on many aspects of the reader. If he or she has good grasp of the language, it is possible for a better understanding of the text. Even then they too face difficulties in reading literature texts due to the cultural familiarity aspect. If the writer is from a different background, students need to be aware of the cultural norms in the author's world to be able to identify language deviance and their significance [2].

Otherwise, this would lead to misinterpretation whereby students tend to interpret the meaning based on their own culture, which might result in inappropriate cultural representation [3]. Thus, the selection of literary texts that is appropriate which tallies students' interest is important for them to explore the texts [4]. Text selection appears to be the most important consideration that must be taken seriously if we seek for a more meaningful engagement with literary texts.

The interest factor of students must take precedence in 
any text selection tasks [5]. When students have strong interest in what they read, they tend to read more. Students who read more are better readers [6]. With regard to positive attitude in reading, reading problems among secondary school students in English Language could be minimized. This could lead the students to the achievement of several objectives laid in the English Language Literature Component by the Ministry of Education [7]. It is stated that by the end of secondary school education, students should be able to give a personal response to the text, show an awareness of how language is used to achieve a particular purpose, reflect upon and draw valuable moral lessons from the issues and concerns of life as portrayed in the literary works and relate them to their lives and understanding and appreciate other cultures with the exposure to short stories, poems, novels and plays.

The present study aimed to address students' view on reading the prose forms prescribed in terms of cultural familiarity of the texts, physical features of the texts, and interest and motivation and to identify students' strengths and weaknesses in reading prose form.

\section{The Reader and the Text}

The transactional theory proposed by Rosenblatt [8] underpins the framework of this study. The act of reading is transactional between the reader and the text that occurs within certain context. According to Rosenblatt [8], meaning does not reside in the text but the reader's interaction with it. To bring out the meaning in a text, the text must be in a state that readers can interact with it. An appropriate text which matches readers' needs paves way for a successful comprehension.

\subsection{Literary Texts}

Literary texts refer to creative work of imagination, poetry, drama, fiction and nonfiction. By reading a literary text student can feel for characters to understand what is going on in the hearts of the characters because they know what stirs their own hearts. They realize that the characters have gone through the same things that they are experiencing or have experienced. This develops an understanding between students and characters in the literary work whereby students get themselves evolved in the development of the storyline. Exposure to different context of literary texts provides the chances for students to understand other cultures, develop tolerance and understanding among human races. Literary texts offer a rich source for language development [9] and help in enhancing students' linguistic skills. In the same vein, Sidhu [10] and Savvidou [11] state that the study of literature unconsciously enhances students' overall linguistic competence including their knowledge of syntax, morphology, semantics and phonetics. Students become familiar with many features of the written language, reading a contextualized body of text. According to Van
[12], working with literary texts, students are exposed to real language originally intended for native speakers and this allows them to become familiar with the target linguistic forms and communicative functions.

\subsection{Text Selection}

A plethora of benefits of studying literature is well laid and to successfully achieve these benefits the selection of literary texts must tally with students' needs and wants [13]. Otherwise, this hinders text comprehension among the students. Therefore, literary texts which engage affectively, challenge cognitively, promote language awareness, and help students to reflect critically and respond imaginatively would be the best choice for students. In the same vein, Elliot [14] points that literary texts should engage readers cognitively and affectively, and suggests that reading materials should be based on what is available to us and what we consider culturally and linguistically appropriate. Lima [15] states that literary texts must bring teaching practices and classroom experience, a creative and meaningful exploration of language. Further, they should cater for a generation of language learners who would be able to critically and creatively make meaning of the texts they read.

\section{Methods}

\subsection{Research Design}

The research design involves quantitative and qualitative research methods in collecting and analyzing data. Quantitative design method involves a cross-sectional survey to obtain the viewpoint from the secondary school students and a retelling session that complies qualitative design is conducted to investigate students' strengths and weaknesses in text comprehension based on the selected prose forms.

\subsection{Research Objectives}

i) To investigate students' views on cultural familiarity and physical features of the texts, interest in reading and students' preferred prose texts.

ii) To identify students' strengths and weaknesses in reading prose form.

\subsection{Research Questions}

i) What are students' views on reading the prose forms prescribed in terms of: cultural familiarity of the texts, physical features of the texts, and interest and motivation?

ii) What are students' strengths and weaknesses in reading the prescribed prose form?

\subsection{Research Samples}

Students from Form One to Form Three were selected as 
respondents in 40 non-residential schools in Perak. The selection of respondents from the schools was based on simple random sampling method comprising both genders from various races, and different social backgrounds. In the second phase of the study a random purposive sampling was carried out to select participants for the retelling session. Based on the process of data saturation whereby adequacy was attained, only six participants were involved.

\subsection{Research Instruments}

A survey questionnaire and wh-questions were developed to collect relevant data from the students. The questionnaire consisting of 150 questions were built and developed based on scholars' views on the relevant field. Students were required to express their views using a five-point Likert scale. The scale allowed the respondents to express how much they agree or disagree with a particular statement of an attitude, belief or judgment.

Comprehension questions were based on the prose form "Cheat" by Allain [16], catered for Form Two students. Six wh-questions were constructed on the criteria set by Irwin and Mitchell [17] who covers the text structure, main ideas (theme of the story), relevant details (characters involved), summary (from the beginning to the end of the story) and generalize beyond the text (moral values portrayed, general opinion of the texts read).

\subsection{Data Analysis}

Descriptive statistics in the form of frequency counts and percentages were used to present and summarize the data from the questionnaire. Data from 450 questionnaires were used in the SPSS statistics software version 20.0 to analyze students' views on three aspects of the literary texts prescribed. The retelling was tape recorded and a tape script was developed. The tape script was assessed based on the criteria set by Irwin and Mitchell's [17], 5-point scoring scale. It provided a holistic evaluation on the participants' ability to identify overall text structure, main ideas, relevant details, summarize and generalize beyond the text. Each retelling assigned a score ranging from a low of 1 to a high of 5. Participants' total marks were counted and analyzed using descriptive statistical analysis in the form of percentages. Data were presented in bar charts to ascertain the retellings of high, middle and low reading ability participants.

\section{Results and Discussion}

\subsection{Students'Views on Cultural Familiarity of the Literary Texts}

Text comprehension is difficult when students come across cultural aspects that are remote to their knowledge. In view of that, it is crucial to find out how familiar students are towards cultural aspect portrayed in the literary texts.

\section{i) Novel}

The data showed $51.1 \%$ agreed that they understand the culture portrayed in the novel. A total of $50.9 \%$ can picture Westerners' way of life through the novel and 50.4\% showed students can differentiate their way of life to the Westerners'. The data showed $32.3 \%$ disagreed that they face problems in understanding the prose because of cultural differences. A total of $51.8 \%$ agreed the novel exposes to the culture that interest them and 30.4\% agreed their way of life is similar to the characters in the novel. The data showed $46.7 \%$ believe the novel enhances rational thinking, critical thinking $46.7 \%$ and creative thinking $54.0 \%$. A total of $50.4 \%$ believe the moral values portrayed help them to be someone useful in future.

\section{ii) Short stories}

A total of $55.3 \%$ of the students could picture the way of Western living and $32.1 \%$ disagreed that they face problems in understanding the short story due to Western culture. The data showed $49.1 \%$ of the students agreed short stories expose them to the culture which interests them. However, $31.4 \%$ of the students are uncertain that their life experiences are similar to characters involved in the short stories. It is enlightening to note that $56.4 \%$ of the students agreed the short stories enhance rational thinking, $50.2 \%$ on critical thinking and $56.6 \%$ on creative thinking. The data showed $47.6 \%$ of the students believed the moral values portrayed in the short stories help them to be a useful person in future.

\section{iii) Poems}

A total of $47.3 \%$ agreed that they understand the culture portrayed in the poems and $50.4 \%$ of the students believed the moral values help them to be a useful person in future.

\section{iv) Drama}

The data showed $42.5 \%$ agreed they understand the culture portrayed and $42.5 \%$ agreed that they could picture the way of Western living. 32.3\% are uncertain that they face problems in comprehension of texts due to cultural differences and $46.0 \%$ of the students agreed that the drama prescribed expose them to cultures, which interest them. The data showed $31.2 \%$ are uncertain that their life experiences are similar to the characters in the drama. A total of $46.5 \%$ believe drama enhances rational thinking and $44.5 \%$ on critical thinking and $52.9 \%$ on creative thinking

\subsubsection{Students' Views on Physical Features of theLiterary Texts \\ i) Cover of the book}

The data showed $59.1 \%$ disagreed the cover of the text is beautiful or expressive. 


\section{ii) Word font}

A total of $67.0 \%$ of the students agreed they are comfortable with the font of the words used in the literary texts.

\section{iii) Prose forms}

A total of $36.5 \%$ disagreed the short stories are not lengthy and $56.6 \%$ believe the pictures in the short stories help them understand the flow of the story. The data showed $59.1 \%$ of the students believe the pictures in the novel help them to understand the flow of the story and $36.7 \%$ disagreed the novel prescribed is not lengthy.

\section{iv) Poems}

A total of $35.6 \%$ of the students agreed the poems are not lengthy and $44.2 \%$ of the students agreed that the meaning of difficult words is comprehensible by referring to the glossary attached at back of the book.

\subsubsection{Students' Interest and Motivation in Reading Literary Texts \\ i) Cover of the book}

Students are quite negative on the cover of literature book. The data showed $63.5 \%$ disagreed the cover attracts them and $61.7 \%$ disagreed that it motivates students to read the texts.

\section{ii) Prose forms}

A total of $36.7 \%$ of the students are interested in reading the short stories but $34.1 \%$ disagreed the technique of writing the short story motivates them to read. The data revealed $53.3 \%$ of the students believe the moral values portrayed in the short stories motivate them in reading. Besides, factors which attract students to read the short stories are the setting $(43.8 \%)$, culture exposed in the prose forms $(46.7 \%)$ and pictures $(53.0 \%)$.

The data revealed $50.9 \%$ are interested in reading the novel. Factors which interest students to read are the technique of writing the novel $(60.0 \%)$, setting discussed $(52.2 \%)$, pictures inserted $(64.4 \%)$ and the data showed

$54.0 \%$ of the students believe the moral values portrayed motivate them to read. On views in the preference of local or foreign prose forms, data showed $(70.1 \%)$ preferred Asian texts and $(65.2 \%)$ pointed out they have less exposure towards these prose forms.

\section{iii) Poems}

A total of $30.5 \%$ are interested to read the poems but $31.4 \%$ of the students are uncertain that the technique of writing the poems motivates them in reading. The data revealed $48.7 \%$ agreed that the moral values portrayed motivate them to read and $38.3 \%$ believed that the setting discussed could also be a reason, which attracts students to read poems. Besides, $51.8 \%$ believed the culture discussed is comprehensible and $56.2 \%$ of the students felt the pictures inserted in the poems attract them to read.

\section{iv) Drama}

The data revealed $56.9 \%$ are interested in reading the drama prescribed and $46.7 \%$ believed the technique of writing the drama interest them to read. A total of $47.6 \%$ of the students are motivated to read the drama because of the moral value portrayed. The figure shows students are attracted to read the drama because of the setting (56.6\%), culture (53.1\%) and pictures inserted (52.2\%).

\subsection{Form Two Students' Strengths and Weaknesses in Reading Prose Texts}

Form Two participants performed well and all scored high in the retelling session. Table 1 shows participants' retelling scores.

Table 1. Form Two participants' retelling score

\begin{tabular}{|c|c|c|c|c|c|c|c|c|}
\hline \multirow[t]{2}{*}{ Participants } & \multicolumn{6}{|c|}{ Questions } & \multirow{2}{*}{$\begin{array}{l}\text { Total } \\
(/ 30)\end{array}$} & \multirow{2}{*}{$\begin{array}{l}\text { Percentage } \\
\text { (Total score } \\
\div 30 \times 100 \text { ) }\end{array}$} \\
\hline & Q1 & Q2 & Q3 & Q4 & Q5 & Q6 & & \\
\hline 1 & 4 & 4 & 4 & 4 & 4 & 4 & 24 & $80 \%$ \\
\hline 2 & 4 & 4 & 4 & 4 & 4 & 4 & 24 & $80 \%$ \\
\hline 3 & 4 & 4 & 4 & 3 & 4 & 3 & 22 & $73 \%$ \\
\hline 4 & 4 & 4 & 4 & 4 & 4 & 4 & 24 & $80 \%$ \\
\hline 5 & 4 & 4 & 4 & 4 & 4 & 4 & 24 & $80 \%$ \\
\hline 6 & 4 & 4 & 4 & 4 & 4 & 4 & 24 & $80 \%$ \\
\hline
\end{tabular}

Based on table 1 for all the questions, Form Two participants achieved level 4 except for questions 4 and 6 , participant 3 achieved level 3. At level 3, participant 3 was able to include some main ideas and details, understand text organization, and it was a fairly, complete retelling based on Irwin and Mitchell [17], 5- point scale. It was very impressive to note that the participants achieved level 4 in their retellings in most of the questions. At level 4 , they were able to include most main ideas and supporting details, sequences properly and understand text organization.

However, none of the participants achieved level 5 where they could infer beyond the text; relate text to own life, give opinion and justify it. To sum up, five of the participants, 1, 2, 4, 5, and 6 scored $80 \%$, indicated a high level of text comprehension. Participant 3 was able to score $73 \%$, which revealed above average comprehension of text. Figure 1 shows Form Two participants' retelling score.

The bar graph shows Form Two participants' retelling score. It is considered a rich retelling among the participants. Five participants, 1, 2, 4, 5 and 6 scored $80 \%$. Participant 3 achieved $73 \%$. The scores revealed good text comprehension among the participants. Data show that participants are able to read and understand the literary texts prescribed. 


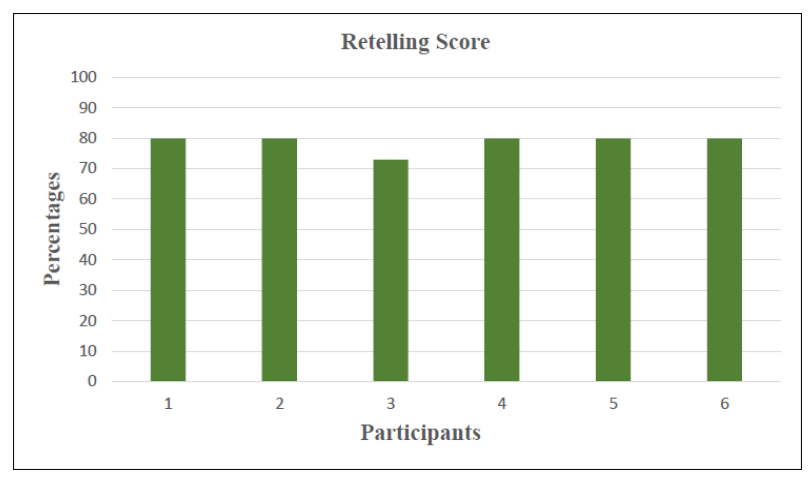

Figure 1. Form Two participants' retelling score

The Form Two participants were able to score level 4 for all questions except for participant 3. The participant achieved level 3 for questions 4 and 6 . The scores in retellings were not below level 3 which means participants were able to sequence the text, identify main ideas and details, and summarize the text based on Irwin and Mitchell [17], 5-point scale. Most of the participants' retellings achieved level 4 . They were able to include most main ideas and supporting details, sequence the story line in order and understand text organization.

\subsection{Discussion on the Findings of Students' View on Three Aspects of Literary Texts and Retellings on Form Two Prose Form}

Based on the data, the findings revealed that lower secondary students are positive towards the selection of literary texts, comprising variety of genres, prose forms (short stories and novel) poems and drama. Despite the positive response, students felt understanding all difficult words in the literary texts are beyond their ability although the meanings of difficult words are given in the glossary.

Besides, students are also uncertain their comprehension towards the literary texts is distant to cultural differences. Students are less exposed to Asian literary texts and fond of foreign texts. Additionally, students find the poems and novel prescribed are lengthy. Besides, it was found that the cover of the text does not play a role in capturing students' interest nor it motivated them to read. Findings from retellings based on the prose form prescribed for Form Two revealed that students' reading and comprehension of the texts is at students' language ability level. Students can understand most main ideas and supporting details, sequence the story line orderly and understand text organization. However, students could not infer beyond the text; relate text to own life, give opinion and justify it.

Based on the results and discussion of the research analysis, the following major conclusion can be drawn on text selection in Malaysian classrooms:

(i) Texts selected should be based on Malaysian and Asian context

(ii) Selection of texts should pose minimal linguistics difficulties and not lengthy (iii) The cover of the texts should be attractive to catch students' eyes

\section{Conclusions}

This research has provided valuable insights in analysing the selection of the current literary texts for students at lower secondary level. The selection of literary texts involves many aspects of readability. If these aspects are not addressed, then teaching and learning of literature could be a difficult task. Students would be burdened by texts which they cannot grasp the meaning from the text [18]. Therefore, text selection should be careful in the sense that it matches students' interest and various age levels [19]. It is found in this study that students have positive views on the literary texts selected for them and text comprehension falls within their language ability level. To infer beyond the texts, students are unable to do so and dissatisfaction among the students is obvious on physical aspects of the literary texts. These data provide evidences for teachers to expose students to teaching and learning activities that enhance students' creative and critical thinking skills, and text selectors should consider the physical aspects in text selection as it is of students' choice. Texts selection that best fits students' choice can derive pleasure and enjoyment in literature teaching and learning.

\section{Acknowledgments}

We are very grateful to the faculty and university for supporting us in this research.

\section{REFERENCES}

[1] Kavitha (2002). Is literature a Viable Medium for ESL Acquisition. Retrieved Mac 21, 2012 from www.languageinindia.com

[2] Hill, Robert (1995). Criteria for the selection of literary texts. Oxford: Oxford University Press

[3] Ganakumaran S. (2003), Literature programmes in Malaysian schools: A historical overview in Ganakumaran, S. \& Malachi Edwin (eds). Teaching of Literature in ESL/EFL Contexts, p. 27-48. Petaling Jaya: Sasbadi Sdn. Bhd.

[4] Lee, S., \& Pulido, D. (2016). The impact of topic interest, L2 proficiency, and gender on EFL incidental vocabulary acquisition through reading. Language Teaching Research, 21(1), 118-135.

[5] Nor Hashimah Isa \& Che Ton Mahmud. (2005). Literary Texts for Malaysian Secondary Schools. Internal Journal of Humanities and Social science, 2(7), Retrieved February 13, 2020 from: http://merr.utm.my/id/eprint/1797 
[6] Cunningham, A. E. \& Stanovich, K.E. (1998). What Reading Does For The Mind. American Educator, 22 (1\&2), 8-15. Retrieved 13 February 2020, from Cunningham Stano American Educator 1998. http://basu.nahad.ir/uploads/cres well.pdf

[7] Ministry of Education Malaysia. (2000). Silibus Komponen Kesusasteraan Bahasa Inggeris. Malaysia.

[8] Rosenblatt, L. (2004). The transactional Theory of Reading and Writing. Theoretical Models and Processes of Reading, International Reading Association, 48, 1363-1398.

[9] Hall, G. (2005). Literature in language education. Basingstoke: Palgrave Macmillan.

[10] Sidhu, G.K. (2003). Literature in the Language Classroom: Seeing Through the Eyes of the Learner. In M.E. Vethamani \& G. Subramaniam (Eds). Teaching of Literature in ESL/EFL Contexts. Petaling Jaya: Sasbadi MELTA ELT Series, 88-110.

[11] Savvidou, C. (2004). An Integrated Approach to Teaching Literature in the EFL Classroom. Accessed on 13 January 2009, from http://iteslj.org/Techniques/SavvidouLiterature.html

[12] Van, Truang. (2009). The Relevance of Literary Analysis to Teaching Literature in the EFL Classroom. English Teaching Forum, 47(3), 2-9.
[13] Mukundu Mukundan, J., Zarifi, A., \& Kalajahi, S. A. R. (2016). Developing Reading Materials for ESL Learners. Issues in Materials Development: Sense Publishers.

[14] Elliot, R. (1990). Encouraging reader-response to literature in ESL situations. ELT Journal, 44/3.

[15] Lima, C. (2010). Selecting Literary Texts for Language Learning. Journal of Nelta, 15(2), 110-113.

[16] Baillie, Allan. (2015). Cheat. Short Story Arena Form 2. Literature Component For Secondary Schools. Kementerian Pendidikan Malaysia

[17] Irwin \& Mitchell (1983), A Procedure for Assessing the Richness of Retellings. Journal of Reading, 26(5), 391-396.

[18] Popp, S. (2018). Teachers' Text Selections and Explanations About text Selection and Use in History/Social Studies. Literacy Research: Theory, Method and Practice. Vol. 67, 279-295.

[19] Nordin., \& Lin. (2017). Text Selection for Teaching Reading To ESL Tertiary Students: A Study On Genre and Content Preferences International Journal of Instruction, 10 (1), 71-78. 